\title{
Regulación de las encuestas electorales: Temas en debate
}

\author{
Samuel B. Abad Yupanqui*
}

Resumen. - El presente artículo analiza la regulación vigente sobre las encuestas electorales, plantea los principales temas en debate y examina las propuestas de reforma presentadas. Resalta que la información que brindan las encuestas es fundamental en una democracia moderna, pues permite conocer la intención de voto de la ciudadanía en un momento determinado. Sus resultados no constituyen un pronóstico de lo que sucederá el día de la elección. Requisitos como la exigencia de un registro y de una ficha técnica resultan razonables. Sin embargo, la prohibición de difundir encuestas hasta el domingo anterior al día de la elección no se ajusta a la Constitución, por afectar derechos fundamentales, y tampoco a la realidad actual. Esta prohibición, introducida en el Perú hace 37 años, amerita ser revisada. Una medida razonable y proporcional debería autorizar la divulgación de encuestas hasta el día anterior a la elección.

\begin{abstract}
This paper analyzes the current regulations on the electoral polls, raises the main issues under debate and examines the reform proposals presented. It highlights that the information provided by polls is fundamental in modern democracy, since it allows to know the voting intention of citizens at any given moment. However, its results do not constitute a certain prediction of the election results. Therefore, requirements such as registry and technical files are reasonable. Nevertheless, the prohibition to disseminate polls until the Sunday before election day contradicts the Constitution, since it affects fundamental rights. This prohibition, which was introduced in in Peru 37 years ago, deserves to be reviewed. A reasonable and proportional measure should authorize the dissemination of polls until the day before the election.
\end{abstract}

Palabras claves. - Encuestas Electorales - Constitución - Elecciones - Reforma Constitucional - Derechos Fundamentales.

Keywords. - Electoral Polls - Constitution - Elections - Constitutional Reform Fundamental Rights.

* Profesor de Derecho Constitucional de la Universidad del Pacífico y de la Pontifica Universidad Católica de Perú. 


\section{Introducción}

Los resultados de las encuestas y la prohibición de divulgarlos días antes de una elección generan debate sobre su real influencia en la opinión pública, su actual regulación y la eficacia de tal prohibición. Suele suceder que los candidatos que no se ven favorecidos con la intención de voto cuestionen su validez, imparcialidad y señalen que no creen en ellas o que la mejor encuesta es el "sentir de la calle", es decir, la opinión que ellos mismos perciben de la ciudadanía. También es frecuente que aparezcan nuevas empresas encuestadoras favoreciendo a un candidato que no se encuentra bien ubicado. $Y$, cuando se inicia la semana en que no pueden ser divulgadas, se difunden resultados -algunos verdaderos, otros falsos- por las redes sociales, por WhatsApp o a través de medios de comunicación de otros países. Es decir, un sector de la población logra estar informado pese a la prohibición legal.

A todos y todas nos interesa conocer los resultados de las encuestas, comparar su evolución y, en no pocas ocasiones, definir el voto en función de ellas. A veces se busca evitar el "voto perdido", es decir, por un candidato o candidata que no tiene mayor opción y se acude a las encuestas para saber quién se encuentra mejor ubicado y tomar una decisión "útil".

De esta manera, las encuestas se han convertido en un importante instrumento de medición de la opinión pública en un momento determinado y cobran especial importancia durante los procesos electorales. Constituyen "un insustituible medio de información" 1 en una democracia moderna, que se divulga fácilmente a través de las redes sociales, internet y los diversos medios de comunicación. ¿Será conveniente regularlas? ¿Habrá que dejar que las empresas encuestadoras libremente se autorregulen? ¿Resulta válido prohibir su difusión hasta el domingo anterior a las elecciones? ¿Será eficaz esta medida si se evidencia la circulación informal de sus resultados por internet y redes sociales? ¿Será una prohibición discriminatoria? ¿Son infalibles y anticipan el resultado de una elección?

El presente artículo, sin ánimo de agotar el debate y desde una perspectiva general, tratará de dar respuesta a estas interrogantes. Se efectuará un análisis jurídico que permita conocer el "estado de la cuestión" sobre la regulación de las encuestas electorales en el Perú y la importancia de efectuar algunos cambios normativos, los cuales se ubican en un contexto mayor: la necesaria reforma política y electoral en el país. Adelantamos que somos partidarios de una regulación de la actividad que desarrollan las empresas e instituciones encuestadoras que no sofoque ni limite su actuación y permita a la ciudadanía ejercer sus derechos de manera informada. La ausencia de regulación o una normatividad desproporcionada no constituyen las medidas más adecuadas. Las encuestas no pueden ser desacreditadas por el hecho que no reflejen exactamente los resultados de una elección o por quienes no aparecen bien ubicados en ellas. No anticipan ni

ARNALDO ALCUBILLA, Enrique. Los sondeos electorales: ¿liberación o reglamentación? en la Constitución de 1993. Análisis y comentarios II. Serie Lecturas sobre Temas Constitucionales 11. Lima: Comisión Andina de Juristas. pp 227. 
vaticinan al ganador. Reiteramos, solo reflejan el estado de la opinión pública en un momento determinado.

\section{Precisiones Conceptuales}

\section{i. Encuestas electorales: concepto y riesgos que pueden presentarse}

Las encuestas permiten contar con información sobre las opiniones de un número determinado de personas respecto a temas de interés en un momento específico. Según el Diccionario de la Real Academia de la Lengua Española, se trata de un "Conjunto de preguntas tipificadas dirigidas a una muestra representativa de grupos sociales, para averiguar estados de opinión o conocer otras cuestiones que les afectan".

Desde las ciencias sociales se afirma que las "encuestas de opinión" son:

“(...) un procedimiento para conseguir información (opiniones) de un grupo de sujetos (muestra) que pretende representar a un universo mayor (población), dentro de márgenes de error controlados (probabilidad). No miden -es bueno precisarlo- la opinión pública, sino opiniones de la población, (...) a lo sumo tienen un valor indicativo" 2 .

Asimismo, se distinguen las encuestas y sondeos de opinión entre políticas y no políticas, y dentro de las encuestas políticas aquellas referidas a la materia electoral y las que no lo son ${ }^{3}$.

Cuando se trata de información electoral, concretamente de "intención de voto" 4 , se denominan "encuestas electorales". Ellas permiten a la ciudadanía ejercer un voto informado, a las agrupaciones políticas evaluar las opiniones del electorado, así como definir las estrategias a seguir, y a los medios de comunicación brindar información sobre el estado de las opiniones de la población en un momento determinado. Incluso "pueden servir como una forma de control democrático allí donde los gobiernos se sienten tentados a manipular fraudulentamente las elecciones" ${ }^{\prime \prime}$.

Como se recuerda, "George Gallup, Elmo Roper y Archibald Crossley llevaron a cabo la primera encuesta electoral de carácter científico en 1936, -con ocasión de las elecciones presidenciales estadounidenses-"6, en las que obtuvo la presidencia Franklin Roosevelt. Veamos:

2 TUESTA, SOLDEVILLA, Fernando. No sabe/ no opina. Encuestas políticas y medios. Lima: Konrad - Adenauer - Stiftung. 1997, pp. 46-47.

3 CÓRDOVA, Lorenzo \& SALAZAR, Pedro. “Consideraciones Generales sobre la (in) justificación de la regulación estatal de las encuestas y sondeos de opinión electorales". En Cuestiones Constitucionales, Núm. 42, 2007, p.16.

4 MARSHALL, Pablo; CHARNEY, John \& ROSAS, Nelson. "Regulación legal de las encuestas electorles: análisis teórico y comparado". En Revista Mexicana de Derecho Constitucional, Núm. 42, enero-junio, 2020, pp. 218.

5 Ibid, 216.

6 GÁLVEZ MUÑOZ, Luis. "Las encuestas electorales y el debate sobre su influencia en las elecciones". En Revista Mexicana de Opinión Pública, Núm 11, 2011, pp.27. 
"Las encuestas electorales de carácter científico, (...), surgieron en los estados Unidos a comienzos de los años treinta, por obra del genial George Gallup, y en muy poco tiempo se convirtieron en unos de los elementos informativos de mayor relevancia durante los procesos electorales en todas las democracias. Su acceso masivo a los medios de comunicación tuvo lugar muy poco después: en los Estados Unidos a partir de 1940, en el reino Unido de 1950 y en el resto de los países democráticos (Francia, Alemania...) en los años sesenta"7.

Las encuestas "no son una predicción o anticipación de los resultados de la consulta electoral, sino una simple fotografía o instantánea de las intenciones de voto de la población en un momento determinado"8. Se discute sobre su real incidencia en la toma de decisiones del electorado y su impacto al momento de efectuar el voto:

“(...) del estudio realizado cabe concluir que las encuestas electorales ocupan un lugar destacado en la decisión electoral de muchos ciudadanos; que los efectos que producen en ellos son de muy distinto tipo y de contrario signo; que esta influencia es susceptible de afectar a los resultados electorales; y que no es posible, sin embargo, predeterminar el sentido de esta influencia, aunque ello no elimina el riesgo de manipulación; $(. . .)^{\prime \prime}$.

Según un informe de la Relatoría para la Libertad de Expresión de la Comisión Interamericana de Derechos Humanos (párrafo 23), "no hay una opinión unánime ni hallazgos concluyentes sobre el impacto que producen los sondeos - y en general, los medios de comunicación - sobre las audiencias" 10 .

Sin embargo, las encuestas podrían presentar algunos riesgos en un sistema democrático que debe garantizar elecciones libres y competitivas, es decir, sin favorecer a determinado candidato o candidata. Estos riesgos pueden ser de distinta naturaleza: "estrictamente intra-metodológicos, principalmente resumidos en la estrategia muestral", "éticos en el levantamiento de datos", "de influencia, principalmente en la intención de voto" y "de interpretación, sobretodo en la cobertura mediática de las encuestas"11. Además, como recuerda Pedro Planas "las encuestas tienen interesados auspiciadores" y "su presencia está lejos de constituir un frío y neutral instrumento técnico"12.

7 GÁlVEZ MUÑOZ, Luis. “Organismos de sondeos, encuestas elecotales y Derecho”. En Revista Mexicana de Estudios Políticos, Núm 110, octubre-diciembre, 2000, pp.97.

8 Ibid, 2017.

9 GÁLVEZ MUÑOZ, Luis. "Las encuestas electorales y el debate sobre su influencia en las elecciones". En Revista Mexicana de Opinión Pública, Núm 11, 2011, pp.41-42.

10 Relatoría Especial para la Libertad de Expresión CIDH. http://www.oas.org/es/cidh/expresion/docs/informes/anuales/Informe\%20Anual\%202005 \%201\%20ESP.pdf.

11 MAYOL, Alberto \& CRESPO, Francesco. “Estándares y regulaciones de las encuestas de opinión pública". En Revistas USACH, Vol. 8, 2015, pp.2-3.

12 PLANAS, Pedro. Comunicación política y equidad electoral. Lima: Universidad de Lima - Fondo de Desarrollo Editorial, 1998, pp. 23. 


\section{ii. ¿Regulación o autorregulación?}

El debate sobre la existencia y alcances de un "marco regulatorio" cuenta con especial relevancia. Los extremos pueden ir desde una "autorregulación", mediante "códigos de conducta y protocolos internacionales"13, hasta una regulación, cuyo contenido dependerá del mayor o menor grado de intervención estatal que ha permitido prohibir su difusión los días previos a la elección. Algunas legislaciones -por ejemplo, la española- circunscriben la aplicación de la regulación sobre encuestas a un periodo determinado: "Entre el día de la convocatoria y el de la celebración de cualquier tipo de elecciones" (Ley Orgánica 5/1985, del Régimen Electoral General, artículo 69).

"Así, los países anglosajones se caracterizan por recurrir a la técnica de la autorregulación, en el sentido que los lineamientos de ética y de calidad de la industria son provistos por la misma comunidad de encuestadores a los que van dirigidos. Este es el caso, por ejemplo, de la práctica de los Estados Unidos de América, Reino Unido y Australia. En la otra vereda, los países que han optado por el camino de la regulación legal para fijar estos criterios reciben en su mayoría inspiración de los principios del derecho continental. Aquí encontramos en la actualidad a gran parte de la comunidad internacional. Conforme al más reciente reporte llevado a cabo a nivel mundial, en 2018 un 60\% de los 133 países consultados contaba con la existencia de embargos o blackouts legales a la publicación de encuestas" 14 .

Como anota Arnaldo Alcubilla, la autorregulación de origen anglosajón se enfrenta a la "opción tuitiva (...) del continente europeo":

“La norma que abrió paso a la reglamentación de las garantías o condiciones técnicas de elaboración y difusión de los sondeos electorales fue la Ley francesa de 19 de julio de 1977, completada por un Decreto de 16 de mayo de 1980, que estableció, por lo demás, una Comisión de Sondeos para velar para que éstos se efectuaran conforme a las citadas reglas en garantía de su seriedad (...)"15.

Una regulación sobre las encuestas electorales es factible. Sin embargo, para ser válida debe tener una finalidad constitucionalmente legítima y respetar derechos y principios básicos, como las libertades de expresión e información, la participación política informada, el principio-derecho de igualdad, la libertad de empresa, la libre competencia, la transparencia, entre otros. Además, debe tomar en cuenta la intervención de diversos actores con perspectivas e intereses distintos (agrupaciones políticas, empresas o instituciones encuestadoras, medios de comunicación, ciudadanía, auspiciadores que contratan las encuestas) incluyendo,

13 MAYOL, Alberto \& CRESPO, Francesco. “Estándares y regulaciones de las encuestas de opinión pública". En Revistas USACH, Vol. 8, 2015, pp.4.

14 MARSHALL, Pablo; CHARNEY, John \& ROSAS, Nelson. "Regulación legal de las encuestas electorles: análisis teórico y comparado". En Revista Mexicana de Derecho Constitucional, Núm. 42, enero-junio, 2020, pp. 225.

15 ARNALDO ALCUBILLA, Enrique. Los sondeos electorales: ¿liberación o reglamentación? en la Constitución de 1993. Análisis y comentarios II. Serie Lecturas sobre Temas Constitucionales 11. Lima: Comisión Andina de Juristas, 1995, pp 230. 
ciertamente, al Estado. En México, por ejemplo, el Instituto Nacional Electoral señala que un "principio central de la regulación ha sido la transparencia y la máxima publicidad con la finalidad de ofrecer a la sociedad los insumos necesarios para que pueda valorar la calidad de ellas y, en consecuencia, contribuir en la construcción del voto razonado y de una opinión pública mejor informada"16.

Como anota el Informe de la Relatoría para la Libertad de Expresión de la CIDH (párrafos 95-96), una regulación de las encuestas electorales debe "siempre propender al fortalecimiento de la libre circulación de información" y evitar que "algunos sectores dispongan de determinada información relacionada con las elecciones mientras que otros -por no poder acceder a ciertos medios de comunicación- se vean privados de las mismas posibilidades" 17 .

Dos de los temas fundamentales que se abordan al momento de regular las encuestas electorales son, por un lado, las "medidas tendentes a garantizar (su) objetividad" y, por otro, la prohibición de su publicación o divulgación en un periodo previo a las elecciones ${ }^{18}$. Se trata de dos medidas claves: (a) el "disclosure o ficha técnica" y, (b) el "blackout o embargo"19.

Dentro de las primeras, la doctrina hace referencia a los "requisitos de publicidad", como, por ejemplo, aquellos establecidos en el artículo 69.1.a de la Ley Orgánica del Régimen Electoral General (España). Vale decir, la exigencia de publicar "la identidad y el domicilio de la persona o entidad que realiza el sondeo y de aquella que lo ha encargado"20. Y, además, los "requisitos técnicos", en otras palabras, las "especificaciones técnicas que deben ser cumplidas a la hora de realizar los sondeos y que deben incorporarse en una ficha técnica de obligatoria publicación junto con los resultados de los mismos"21.

También se discute sobre si la regulación solo debe comprender las encuestas y sondeos de opinión que registran la "intención de voto" o incluir "otro tipo de

16 Extraído de https://www.ine.mx/voto-y-elecciones/encuestas-electorales/

17 Relatoría Especial para la Libertad de Expresión, opi.cit., p. 187.

18 SÁNCHEZ MUÑOZ, Oscar. La igualdad de oportunidades en las competiciones electorales. Madrid: Centro de Estudios Políticos y Constitucionales, 2007, pp.315.

19 MARSHALL, Pablo; CHARNEY, John \& ROSAS, Nelson. “Regulación legal de las encuestas electorles: análisis teórico y comparado". En Revista Mexicana de Derecho Constitucional, Núm. 42, enero-junio, 2020, pp. 221.

20 "Artículo 69.-

$(\ldots)$

1. Los realizadores de todo sondeo o encuesta deben, bajo su propia responsabilidad, acompañarla de las siguientes especificaciones, que asimismo deben incluir toda publicación de las mismas:

a) Denominación y domicilio del organismo o entidad, pública o privada de la persona física que haya realizado el sondeo, así como de.la que haya encargado su realización.

b) Características técnicas del sondeo, que incluyan necesariamente los siguientes extremos: sistema de muestreo, tamaño de la muestra, margen de error de la misma, nivel de representatividad, procedimiento de selección de los encuestados y fecha de realización del trabajo de campo.

c) Texto íntegro de las cuestiones planteadas y número de personas que no han contestado a cada una de ellas."

21 SÁNCHEZ MUÑOZ, Oscar. La igualdad de oportunidades en las competiciones electorales. Madrid: Centro de Estudios Políticos y Constitucionales, 2007, pp.316. 
sondeos (...), como los de ganador-perdedor de los debates, o proyecciones de voto basadas en datos no procedentes de encuestas, sondeos que, (...), también pueden condicionar a los electores"22. En México, por ejemplo, el Reglamento de Elecciones regula las "encuestas por muestreo, sondeos de opinión, encuestas de salida y conteos rápidos no institucionales" (artículo 132 y siguientes).

Un aspecto polémico es la prohibición legal de la difusión de encuestas antes de la elección. Este periodo se conoce como "jornada de reflexión"23. Se discute la validez constitucional de esta prohibición -incluso, se distingue una prohibición con plazos extensos de otra con plazos reducidos- y su eficacia debido, por ejemplo, al impacto de la tecnología (redes sociales, internet, etc.) y a la globalización de la información. Al respecto, podemos distinguir "sistemas prohibicionistas" y "sistemas liberales" que desarrollan una opción u otra. Estos últimos no establecen "ninguna limitación temporal a la divulgación de encuestas electorales, de tal modo que incluso el día de las elecciones los ciudadanos pueden leer en los periódicos los resultados de las últimas encuestas realizadas"24.

En América Latina, destaca la experiencia colombiana. La Corte Constitucional declaró inconstitucional la prohibición legal de divulgar encuestas electorales treinta días antes de las elecciones ${ }^{25}$. Posteriormente, al revisar la una ley que estableció un plazo menor (siete días) consideró que esta medida sí resultaba válida ${ }^{26}$ :

"Atendiendo a que la restricción en este caso no es de 30 días, sino de 7, la Corte Constitucional considera que el precedente jurisprudencial no es aplicable, pues evidencia que la restricción al derecho de información no es desproporcionada. (...) la disposición se ajusta a la Carta y es proporcionada al fin perseguido, al permitir a los electores contar con una semana de reflexión para definir, sin la presión de los resultados de las encuestas, su preferencia electoral. "

En el Perú, adelantamos, el primer párrafo del artículo 191 de la Ley Orgánica de Elecciones, dispone que la divulgación solo "puede efectuarse hasta el domingo anterior al día de las elecciones" 27 . Una medida que consideramos inconstitucional.

Además, es importante determinar con claridad las atribuciones de los organismos electorales. La existencia de una regulación, sin los organismos de control necesarios y que no determine las infracciones y sanciones susceptibles de aplicarse, carece de sentido. La tesis según la cual "el mejor control (...) es el

22 SÁNCHEZ MUÑOZ, Oscar. La igualdad de oportunidades en las competiciones electorales. Madrid: Centro de Estudios Políticos y Constitucionales, 2007, pp.322.

23 PLANAS, Pedro. Normas para regular la campaña electoral, en TUESTA SOLDEVILLA Fernando (Editor), “Simposio sobre Reforma Electoral”, Lima: IFES - USAID 1996, pp. 225.

24 GÁLVEZ MUÑOZ, Luis. "La prohibición de difundir encuestas electorales: ¿una norma inconstitucional?”. En Revista de las Cortes Generales, Núm 41, 1997, pp.47.

25 Sentencia C-089-1994

26 Sentencia C-1153-2005

27 Artículo 191 de la Ley Orgánica de Elecciones N. 26859: La publicación o difusión de encuestas y proyecciones de cualquier naturaleza sobre los resultados de las elecciones a través de los medios de comunicación puede efectuarse hasta el domingo anterior al día de las elecciones. 
mercado" no es suficiente 28 . Al respecto, la Corte Constitucional de Colombia precisó que:

“(...) la vigilancia que se ordena sobre las entidades o personas que se ocupan profesionalmente de realizar encuestas, lo mismo que la consagración de sanciones como consecuencia de la inobservancia del precepto, en modo alguno violan la Constitución. Las disposiciones revisadas buscan preservar la autenticidad y objetividad de las encuestas y evitar que ellas den pábulo a la distorsión informativa" 29 .

Una adecuada fiscalización debe ser respetuosa de principios y derechos básicos como la libertad de empresa, la libre competencia, las libertades de expresión e información y el debido proceso. La regulación no evita que las encuestas presenten resultados distintos a los oficiales pues se suelen realizar en fechas anteriores al día de la elección y el sentido de la opinión pública puede variar, tal como sucede con los "indecisos" que el mismo día de la votación se inclina por una determinada opción electoral. Como anota, un Informe del Relator para la Libertad de Expresión de la OEA (párrafo 21):

“(...) ha habido numerosas fallas históricas: en 1948 todas las empresas predijeron la derrota de Harry Truman en los Estados Unidos; en 1990 la mayor parte de las encuestas predijeron el triunfo Sandinista sobre Violeta Chamorro en Nicaragua; en 1970 las encuestadoras se equivocaron al pronosticar la victoria laborista sobre los conservadores en Gran Bretaña, entre otros casos. ¿Esto significa que las encuestas no sirven? En realidad, la mayoría de los expertos señalan que - históricamente - los aciertos han sido mayores que los errores. (...), las encuestas ayudan a comprender la realidad, a establecer tendencias y a analizar lo que ocurre dentro de un proceso electoral" 30 .

Ello no justifica su eliminación o desprestigio, sino más bien debe conducir a establecer una razonable regulación, así como exige el adecuado funcionamiento de los organismos de fiscalización ante eventuales incumplimientos legales. Y es que las encuestas no reemplazan a los organismos electorales ni constituyen un oráculo que vaticine el resultado de una elección. Se trata de "mediciones de las preferencias manifiestas de una muestra de la población específica en un momento determinado $y,(. .$.$) , no constituyen en sí mismas un pronóstico" 31$. A ello se agrega que, en países como el nuestro, es frecuente que el voto se defina los días cercanos o el mismo día de la elección.

28 DURÁN BARBA, Jaime. “Encuestas electorales”. En Diccionario Electoral, Tomo Im 2000, pp. 497.

29 Sentencia C-089-1994, op.cit., párrafo 6.10

30 Relatoría Especial para la Libertad de Expresión, opi.cit., p. 161.

31 DE LA PEÑA, Ricardo \& ORTIZ ORTEGA, Verónica. “Sobre la regulación federal de las encuestas electorales en Mexico". En Revista del Tribunal Electoral del Poder Judicial de la Federación, Vol. 1, Núm 11, noviembre-febrero, 2013, pp. 194. 


\section{Regulación legal y reglamentación efectuada por el Jurado Nacional de Elecciones}

\section{i. Origen y alcances de la prohibición legal de difundir encuestas electorales. Su carácter inconstitucional.}

La prohibición de difundir encuestas días antes de la elección aparece en 1984, a través de la Ley $N^{\circ} 23903$, publicada el 25 de agosto. Como anota Fernando Tuesta:

"¿qué ha ocurrido entre los pronósticos de las compañías encuestadoras y los resultados finales de las elecciones desde la aparición de éstas el año 80? Una cosa es clara: en todas ellas sólo algunas pocas compañias han logrado acercarse a los resultados finales; la mayoría de ellas estuvieron lejos de éstos"32.

Agrega que "muchas de estas compañías encuestadoras son empresas privadas y, como es lógico suponer, buscan maximizar sus ganancias y reducir costos", dependiendo de los métodos empleados los márgenes de error pueden ser muy $\operatorname{altos}^{33}$.

Durante el gobierno del Presidente Fernando Belaunde Terry (1980-1985), que asumió el poder luego del régimen militar (octubre 1968 - julio 1980), se aprobó la Ley $\mathrm{N}^{\circ} 23903$ (1984). Ella mantuvo la vigencia del Decreto Ley $\mathrm{N}^{\circ} 14250$, Estatuto Electoral, de 05 de diciembre de 1962, con sus modificatorias y ampliatorias, dispuso que el JNE publicaría una edición concordada de dicho Decreto (artículo 21), e incorporó un dispositivo sobre las encuestas, según el cual:

Artículo 22.- La publicación o difusión de encuestas y proyecciones de cualquier naturaleza, sobre los resultados de las elecciones, a través de los medios de comunicación, sólo podrá efectuarse hasta 15 días antes de la elección.

Diez años después, el artículo 6 de la Ley 26337, publicada el 23 de julio de 1994, autorizó al JNE a publicar el Texto Único Ordenado -TUO- del Decreto Ley 14250. El tercer y último párrafo del artículo 206 del mencionado TUO ${ }^{34}$, incorporó el texto del artículo 22 de la Ley $N^{\circ} 23903$.

La vigente Ley Orgánica de Elecciones, Ley 26859 de 01 de octubre de 1997, cuenta con un solo artículo referido a las encuestas electorales (artículo 191). El texto del citado artículo, antes de su modificación por la Ley $\mathrm{N}^{\circ} 27369$ (2000), disponía que:

"La publicación o difusión de encuestas y proyecciones de cualquier naturaleza, sobre los resultados de las elecciones, a través de los medios de comunicación, sólo puede

32 TUESTA, SOLDEVILLA, Fernando. Perú político en cifras. Lima: Fundación Friedrich Ebert. Segunda edición, 1994, pp. 25.

33 Idem.

34 La versión original del artículo 206 del Decreto Ley N 14250 disponía que: “Desde dos días antes del señalado para las elecciones se suspenderá toda clase de propaganda política. Dentro del mismo plazo no podrán efectuarse reuniones o manifestaciones púbicas de carácter político". No hacía mención alguna a las encuestas electorales. 
efectuarse hasta 15 (quince) días antes del día de la elección. En caso de incumplimiento se sancionará al infractor con una multa que fijará el Jurado Nacional de Elecciones tomando como referencia la Unidad Impositiva Tributaria (UIT); lo recaudado constituirá recursos propios de dicho órgano electoral."

El proceso de elaboración de la citada Ley 26859 tomó en cuenta diversos proyectos presentados al Congreso, algunos de los cuales permitían la difusión de las encuestas electorales hasta 24 horas de la fecha de la elección ${ }^{35}$, derogaban las disposiciones que prohibían su difusión ${ }^{36}$ o derogaban el artículo 22 de la Ley 2390337. El dictamen de la Comisión de Constitución y Reglamento del Congreso del 25 de marzo de 1997 (artículo 221) dispuso que "La publicación o difusión de encuestas y proyecciones de cualquier naturaleza, sobre los resultados de las elecciones, a través de los medios de comunicación, solo puede efectuarse hasta 3 días antes del día de la elección". Esta propuesta motivó el cuestionamiento del presidente del Jurado Nacional de Elecciones, Álvaro Chocano Marina, a través del Oficio 118-97-P/JNE de 17 de abril de 1997:

“26. Se observa el Artículo $221^{\circ}$ del proyecto, al advertir que la difusión de encuestas y proyección de cualquier naturaleza sobre los resultados de las elecciones puede influenciar subliminalmente en el electorado, resultando conveniente que se amplie el plazo de prohibición de publicación de tres (03) días a siete (07) días antes de la fecha de las elecciones, de acuerdo con el Derecho Comparado que mayoritariamente se pronuncia en ese sentido. Asimismo, se considera que debe fijarse sanciones para los infractores y que los montos recaudados constituyan recursos propios del Jurado Nacional de Elecciones" 38 .

Si bien la redacción de la versión aprobada por el Congreso se basó, en gran medida, en lo planteado por el JNE, mantuvo el plazo prohibitivo de quince días previos al día de la elección introducido desde 1984.

El texto vigente del artículo 191 redujo el plazo de 15 días. Fue incorporado por el artículo 17 de la Ley 27369, publicada el 18 de noviembre del 2000, en los términos siguientes:

Artículo 191.- La publicación o difusión de encuestas y proyecciones de cualquier naturaleza sobre los resultados de las elecciones a través de los medios de comunicación puede efectuarse hasta el domingo anterior al día de las elecciones.

$(\ldots)$

35 Proyecto $N^{\circ} 2534 / 96-C R$ presentado el 26 de febrero de 1997

36 Proyecto 045/95-CR presentado el 7 de agosto de 1995

37 Proyecto No 1668/96-CR presentado el 22 de agosto de 1996

38

https://www2.congreso.gob.pe/Sicr/TraDocEstProc/tradoc_condoc_1995.nsf/0/bc0ae7b5002 0ec2a052580bc005e9b4b/ \$FILE/OFICIO118-97-P-JNE.pdf. Consulta realizada el día 19 de julio de 2021. Jurado Nacional De Elecciones 
En caso de incumplimiento, se sancionará al infractor con una multa entre 10 y 100 Unidades Impositivas Tributarias que fijará el Jurado Nacional de Elecciones; lo recaudado constituirá recursos propios de dicho órgano electoral.

El Proyecto de Ley 737 presentado el 08 de noviembre del 2000, que dio origen a la Ley 27369, fue elaborado en el marco del trabajo desarrollado por la Mesa de Diálogo de la Organización de Estados Americanos (OEA), integrada por diversas agrupaciones políticas y representantes de la sociedad civil, luego de las fraudulentas elecciones del año 2000 que favorecieron a Alberto Fujimori y que motivaron el cuestionamiento de la comunidad internacional y de instituciones nacionales como la Defensoría del Pueblo ${ }^{39}$. El texto fue aprobado por el Pleno del Congreso de la República en la 2-B Sesión vespertina realizada el 13 de noviembre del 2000, con la finalidad de establecer las reglas electorales que regirían el año $2001^{40}$. El entonces congresista Jorge del Castillo, quien formó parte del grupo de trabajo de la Mesa de Diálogo, sustentó la propuesta en la indicada sesión del Pleno del Congreso señalando:

"El artículo 17. es una novedad en este proyecto, porque reduce de 15 a 6 días el periodo de embargo $P$ las encuestas. O sea, se puede difundir encuestas hasta el domingo anterior al día de la elección" 41.

El primer párrafo del artículo 191, modificado hace 21 años, mantiene una regla prohibitiva que pretende, como veremos, evitar una "desorientación en el electorado, "deformar la voluntad electoral" o generar distorsiones ${ }^{42}$. A nuestro juicio, tal como sucede en otros países ${ }^{43}$, prohibir la difusión los días previos a una elección es una medida inconstitucional. Vulnera los derechos fundamentales a la libre expresión (impide la difusión de los resultados de las encuestas), información (evita que la ciudadanía conozca tales resultados) e igualdad (solo algunas personas tienen acceso a ellas).

Esta prohibición legal no supera un test de proporcionalidad el cual, siguiendo a Bernal Pulido44, cuenta con tres "subprincipios" (idoneidad, necesidad y proporcionalidad en sentido estricto ${ }^{45}$. Podemos admitir que cuenta con una

39 El Informe de Observación Electoral de la OEA de 31 de mayo señaló que "de acuerdo a los estándares internacionales, el proceso electoral peruano está lejos de ser considerado como libre y justo". El reporte del 4 de junio de la Comisión Interamericana de Derechos Humanos precisó que "el proceso electoral en el Perú constituye claramente una interrupción irregular del proceso democrático" (Defensoría del Pueblo, 2000: 153).

40 Congreso de la República. 2000. Diario de Debates del Pleno, 2B (Sesión vespertina), Lima 13 de noviembre. Pag 188.

41 Ibid, 185.

42 NOLTE, Detlef. Encuestas y sondeos durante el proceso electoral, en NOHLEN Dieter, Sonia Picado y Daniel Zovatto (Compiladores), “Tratado de derecho electoral comparado de América Latina", México: IIDH, Universidad de Heidelberg, IFE, Fondo de Cultura Económica, 2005, 649.

43 CORZO SOSA, Edgar. "Las encuestas electorales y los derechos fundamentales. Una primera reflexión". En Cuestiones Constitucionales, 16, enero-junio 2007.

44 BERNAL PULIDO, Carlos. El principio de proporcionalidad y los derechos fundamentales. Madrid: Centro de Estudios Políticos y Constitucionales, 2005, 881.

45 "1. (...) idoneidad, toda intervención en los derechos fundamentales debe ser adecuada para contribuir a la obtención de un fin constitucionalmente legítimo. 
finalidad constitucionalmente legitima, es decir, tal como sucede en otros países, sería una medida protectora destinada a "permitir al ciudadano recuperar su libertad de decisión sin presiones o influencias directas, indirectas o de ninguna especie"46, "garantizar la racionalidad de la decisión del elector"47, o evitar "influenciar subliminalmente en el electorado" (JNE, 1997: 17). Y, además, podría considerarse que dicha prohibición -en teoría- sería idónea para alcanzar tal finalidad. Sin embargo, la misma no respeta el subprincipio de necesidad.

En efecto, para que "una injerencia en los derechos fundamentales sea necesaria, no debe existir ningún otro medio alternativo que revista, por lo menos, la misma idoneidad para alcanzar el objetivo propuesto y que sea más benigno con el derecho afectado"48. A nuestro juicio, existe una alternativa idónea y menos grave que sí estaría ajustada a la Constitución, y que consistiría en permitir la divulgación de las encuestas hasta el día anterior a la fecha de la elección. Por lo demás, en la medida que no superar el test de necesidad, ya no sería relevante evaluar la proporcionalidad en sentido estricto.

Un valioso informe de octubre de 2018, elaborado por la Clínica Jurídica de la Facultad de Derecho de la Universidad del Pacífico, liderada por el profesor Andrés Calderón, también considera que se trata de una prohibición inconstitucional y propone su derogación ${ }^{49}$.

¿Qué hacer frente a esta inconstitucional prohibición? No podría interponerse una demanda de inconstitucionalidad ante el Tribunal Constitucional, pues ya venció el plazo de seis años para hacerlo (artículo 100, Código Procesal Constitucional). Sí podría presentarse una demanda de amparo contra norma autoaplicativa, ante la inminencia de su aplicación, y siempre que se sustenten los presupuestos que justifican su procedencia. Precisamente, el 21 de mayo del 2021, con motivo de las elecciones generales, se interpuso una demanda de solicitando su inaplicación, que fue rechazada liminarmente. El Primer Juzgado Especializado en lo Constitucional de Lima (Exp. No 01906-2021) consideró que resultaba manifiestamente improcedente (Resolución $N^{\circ} 1$ de 24 de mayo de 202150). La resolución fue

2. (...) necesidad, toda medida de intervención en los derechos fundamentales debe ser la más benigna con el derecho intervenido, entre todas aquellas que revisten por lo menos la misma idoneidad para alcanzar el objetivo propuesto.

3. (...) proporcionalidad en sentido estricto, (...), las ventajas que se obtienen mediante la intervención en el derecho fundamental deben compensar los sacrificios que ésta implica para sus titulares y para la sociedad en general" BERNAL PULIDO, Carlos. El principio de proporcionalidad y los derechos fundamentales. Madrid: Centro de Estudios Políticos y Constitucionales, 2005, 881.

En sentido similar, se ha pronunciado el TC (STC N00048-2004-PI, FJ 65).

46 PLANAS, Pedro. Normas para regular la campaña electoral, en TUESTA SOLDEVILLA Fernando (Editor), “Simposio sobre Reforma Electoral”, Lima: IFES - USAID 1996, pp. 225.

47 PLANAS, Pedro. Comunicación política y equidad electoral. Lima: Universidad de Lima - Fondo de Desarrollo Editorial, 1998, pp. 25.

48 Sentencia N00048-2004-PI, FJ 65

49 Extraído de https://clinicajuridica.up.edu.pe/wp-content/uploads/2020/11/InformeDifusion-de-Encuestas-Clinica-Juridica-UP-Octubre-2018.pdf. Consulta realizada el día 19 de julio de 2021. Clínica jurídica de la facultad de Derecho de la Universidad del Pacífico.

50 CUARTO. - 
apelada, pero las elecciones ya se realizaron y la prohibición, obviamente, mantuvo su vigencia.

En plena sociedad de la información, este tipo de medidas prohibitivas no son eficaces. Como lo reconoció la Corte Constitucional de Colombia, una prohibición de esta naturaleza constituye una medida de carácter "inocuo" y "contraproducente".

“(...) con los avances en el campo de las telecomunicaciones podría difundirse, por ejemplo, desde estaciones emisoras extranjeras la información que se prohíbe, y ello se haría por tanto a través de medios no controlados en su emisión por el Estado colombiano. Es ineficaz tratar de prohibir que se difundan unas encuestas -que interesan a todos y para cuya transmisión hay demanda segura- por un término desproporcionado. Ello resultaría, además, contraproducente, por cuanto dicha prohibición fomentaría la circulación de informaciones clandestinas, de rumores y especulaciones imposibles de ser controlados en su objetividad por el Estado; en otras palabras, si se cierran los cauces naturales de opinión, se abrirán subrepticiamente mecanismos que los expresen, con el peligro de que no sean veraces sino distorsionadas o exageradas las informaciones que se difundan y así la objetividad desaparezca." 51

En consecuencia, nos parece una alternativa razonable permitir la difusión de resultados de encuestas electoral hasta el día anterior a la fecha de elecciones y el mismo día permitirlas cuando culmine el proceso de votación. Esta propuesta supera el test de proporcionalidad.

De otro lado, el segundo párrafo del artículo 191 en la parte que disponía "El día de la elección sólo se pueden difundir proyecciones basadas en el muestreo de las actas electorales luego de la difusión del primer conteo rápido que efectúe la ONPE o a partir de las 22:00 horas, lo que ocurra primero", fue declarado inconstitucional por el Tribunal Constitucional ante una demanda presentada el 7 de marzo del 2001 por la Defensoría del Pueblo52. Según el Tribunal, dicha norma vulneraba:

“12. (...) el principio de igualdad (...), esta prohibición se circunscribe al territorio del Estado peruano, y no alcanza a las proyecciones difundidas en medios de prensa de Estados extranjeros; por lo tanto, la información de proyecciones difundidas por dichos medios podrá ser obtenida a través del "internet" o de televisión por cable; de este modo, la prohibición establecida por la norma impugnada, tendría como resultado que determinado sector de la población -el minoritario- pueda acceder a estos medios, aún privilegiados, y el otro -el mayoritario- que no pueda efectuarlo.

(...) al no cumplirse con el presupuesto que requiere la amenaza de violación de un derecho constitucional, conforme a lo desarrollado por el Tribunal Constitucional en la sentencia antes indicada, los hechos y el petitorio de la demanda no están referidos al contenido constitucionalmente protegido de los derechos que se invocan como afectados por los demandantes.

Siendo ello así, se configura el supuesto de improcedencia que describe el artículo 5 inciso $1^{\circ}$ del Código Procesal Constitucional.

51 Corte Constitucional de Colombia. Sentencia Nº C-488-1993, párrafo 6.3.7

52 Sentencia $\mathrm{N}^{\circ} 0002-2001-\mathrm{AI} / \mathrm{TC}$ de 04 de abril de 2001 
La circunstancia que determinará que el ciudadano pueda incluirse dentro de uno u otro sector es, fundamentalmente, (...), su condición o posibilidad económica $y$, además cultural, en el caso del acceso a internet; económica, en tanto el acceso a dichos medios (televisión por cable e internet) supone el pago de servicios cuyas tarifas no están precisamente al alcance de la capacidad económica de la totalidad de la población; cultural, porque el acceso a internet exige un mínimo de aprestamiento técnico o capacitación del que carecen aún grandes sectores de la población peruana, teniendo en cuenta a tal efecto el predominante "analfabetismo informático" del que ésta aún padece (...)"

El referido caso tuvo una especial relevancia pues permitió conocer los sondeos a "boca de urna" el mismo día de las elecciones. Fue resuelto en solo 28 días ante la urgencia por la cercanía de las elecciones ${ }^{53}$.

\section{ii. Registro, obligaciones y control de empresas e instituciones encuestadoras}

El artículo 18 de la Ley 27369, que modificó la Ley Orgánica de Elecciones, establece la obligación de las empresas encuestadoras de inscribirse ante el JNE:

Artículo 18.- Elaboración de encuestas

Toda persona o institución que realice encuestas electorales para su difusión debe inscribirse ante el Jurado Nacional de Elecciones. Para el efecto deberá acreditar su denominación y domicilio.

Todas las encuestas o sondeos publicados o difundidos deberán contener claramente el nombre del encuestador y la ficha técnica, que deberá indicar la fecha, el sistema de muestreo, el tamaño, nivel de representatividad y el margen de error, así como otras normas que determine el Jurado Nacional de Elecciones.

Sólo podrán publicarse encuestas cuando la persona o institución estén debidamente inscritas.

El Jurado Nacional de Elecciones podrá suspender del registro antes mencionado a la persona o institución que realice encuestas electorales para su difusión y que no se ajusten estrictamente a los procedimientos normados.

Esta norma creó un registro y otorgó competencia al JNE para regular y fiscalizar a las personas e instituciones que realizan encuestas electorales. El citado artículo se originó en el Proyecto de Ley $\mathrm{N}^{\circ} 737$, elaborado en el marco del trabajo desarrollado por la Mesa de Diálogo de la OEA y fue aprobado por el Congreso el 13 de noviembre del 2000. El entonces congresista Jorge del Castillo, sustentó la propuesta:

53 DEFENSORÍA DEL PUEBLO. Redibujando la institucionalidad democrática: derecho, verdad y participación ciudadana. Cuarto Informe del defensor del Pueblo al Congreso de la República 2000 - 2001 Perú. Lima: Defensoría del Pueblo, 2001, 924. 
"En el artículo 18 se crea un mecanismo de registro de las empresas encuestadoras. Este es un tema que algunas personas pueden haber criticado, pero nos parece básico que exista un registro y haya normas elementales para las empresas encuestadoras, porque hemos visto que en pasadas elecciones se ha dado casos de empresas inexistentes que hacen encuestas fantasmas, y trafican realmente con la voluntad popular. Entendemos que esto va a poner restricciones a esa liberalidad realmente ilegítima"54.

Durante el debate en el Congreso, el entonces congresista Valentín Paniagua defendía la propuesta:

“(...) nadie podrá negar que en el Perú era indispensable establecer algunos principios dentro de la ley para dar facilidades, en unos casos, e incluso para defender, en otros, a las propias encuestadoras de la competencia desleal; puesto que, en este país, en época electoral, como hongos después de la tempestad, aparecen empresas encuestadoras que no tiene registro, que no tienen seriedad y que, naturalmente, confunden al electorado."

Establecer un registro en el Jurado Nacional de Elecciones para las encuestadoras solamente no es una manera de restringir el derecho de estas empresas, es defenderlas ${ }^{55}$.

El congresista Del Castillo refiriéndose al registro señalaba que:

“(...) es para garantizar que cada vez que hay una encuesta las empresas acrediten el universo de trabajo, las condiciones minimas en las que ese trabajo se ha desarrollado, y lo registren ahí para que cualquier persona pueda tener después el derecho -porque será un registro público- a verificar las condiciones que se realizó esa labor" 56 .

Finalmente, el texto fue aprobado por el Pleno del Congreso y se convirtió en la Ley $\mathrm{N}^{\circ} 27369$.

$\mathrm{Al}$ amparo de dicha regulación, el JNE a través de la Resolución N 142-2001-JNE, publicada el 10 de febrero de 2001, creó el "Registro Electoral de Encuestadoras" (artículo 1) y aprobó su primer Reglamento (artículo 2) que contaba con quince artículos. El registro está a cargo de la Dirección Central de Gestión Institucional del JNE, conforme lo establece su Reglamento de Organización y Funciones (Resolución 001-2016-JNE, modificada por Resolución 0337-2017-JNE). Posteriormente, la Resolución 435-2014-JNE, de 30 de mayo de 2014, modificada por la Resolución 0296-2017-JNE, aprobó un nuevo Reglamento. Este último fue derogado por la Resolución 0462-2017-JNE, publicada en "El Peruano" el 15 de diciembre del 2017.

54 Congreso de la República. 2000. Diario de Debates del Pleno, 2B (Sesión vespertina), Lima 13 de noviembre. Pag 188.

55 Ibid, 248.

56 Congreso de la República. 2000. Diario de Debates del Pleno, 2B (Sesión vespertina), Lima 13 de noviembre. pp.251. 
El actual Reglamento sobre Encuestas Electorales durante los Procesos Electorales, fue aprobado por Resolución 0309-2020-JNE, publicado el 9 de setiembre del 2020 y deja sin efecto la Resolución 0462-2017-JNE. Tiene cincuenta artículos, dos disposiciones transitorias y una disposición final. Su finalidad es "verificar el cumplimiento de las obligaciones, prohibiciones o limitaciones exigibles a las encuestadoras, en la difusión de las encuestas electorales sobre intención de voto y simulacro de votación durante los procesos electorales, determinar las medidas correctivas; e, imponer sanción ante la infracción cometida" (artículo 2).

Conforme fluye del octavo y noveno considerandos de la Resolución que lo aprueba, "Dada la coyuntura actual, se ha considerado conveniente incluir medios tecnológicos para la toma de información a los ciudadanos sobre el estudio de encuestas electorales que las encuestadoras formulen y que serán pasibles de fiscalización por el Jurado Nacional de Elecciones". Es decir, la realización de las encuestas debe adaptarse a la situación de pandemia que vive el país.

Las encuestadoras inscritas en el Registro Electoral de Encuestadoras "son las únicas facultadas a elaborar las encuestas electorales sobre intención de voto (presencial y/o teléfono) y simulacro de votación para su difusión, con motivo de un proceso electoral" (artículo 10). Deben presentar un "informe dentro de los cinco (5) días hábiles posteriores a la fecha de publicación de la encuesta electoral" (artículo 19), cuyo contenido se detalla en los artículos 21 y 22. Además, precisa los "requisitos de la ficha técnica para la encuesta sobre intención de voto (presencial y/o teléfono) y simulacro de votación" (artículo 23).

El artículo 41 establece el régimen de infracciones y sanciones. Así, por ejemplo, si una empresa encuestadora o un medio de comunicación "publican o difunden encuestas de cualquier naturaleza sobre los resultados de las elecciones a través de cualquier medio con posterioridad al domingo anterior al día de las elecciones" se le aplicará una multa entre 10 y 100 UIT. Agrega que "Se considera como presunto infractor al representante legal de la encuestadora, si es persona jurídica; en caso contrario, a la persona natural. De ser el caso el representante del medio de comunicación que difunda la encuesta electoral y/o simulacro de votación en periodo prohibido." (artículo 42).

El procedimiento sancionador se inicia ante el Jurado Electoral Especial (artículo 43) que resuelve en primera instancia (artículo 44) y, en instancia final, el Jurado Nacional de Elecciones (artículos 47 y 48). La Dirección Central de Gestión Institucional del JNE asume la competencia de los Jurados Electorales Especiales si no se encuentran instalados (artículo 8).

\section{Propuestas de Reforma Legal}

i. El Anteproyecto de Código Electoral del Jurado Nacional de Elecciones y el Proyecto de Ley presentado por el Ejecutivo elaborado por la Comisión para la Reforma Política 
Desde el año 2011, el Jurado Nacional de Elecciones viene proponiendo la aprobación de un Código Electoral que sistematice, actualice y mejore sustancialmente la normatividad vigente. Pese a su relevancia, hasta el momento no se ha concretado. No ha existido voluntad política del Congreso para hacerlo. La propuesta se ha ido actualizando y se ha concretado en el Anteproyecto de Ley de Código Electoral 202057. Desde la propuesta del 2011 se ha tratado de regular con más detalle las encuestas electorales. Veamos.

El Proyecto de Código Electoral presentado por el JNE el 29 de noviembre de 2011 al Congreso de la República (Proyecto N 590-2011-JNE) contaba con un capítulo (Título VIII PROCESOS ELECTORALES, Capítulo VI ENCUESTAS) referido a las encuestas (artículos 366 a 376). La Exposición de Motivos del citado Proyecto señalaba que:

“(...) opta por regular de manera específica y detallada las encuestas y la actividad de los encuestadores. Al respecto, son antecedentes de dicha regulación los reglamentos del Registro Electoral de Encuestadoras, tanto de la aprobada con la Resolución $N^{\circ}$ 390-205-JNE, como la vigente Resolución $N^{\circ}$ 5011-2010-JNE, así como la legislación comparada, en especial el caso francés, español, el brasileño o el costarricense" .58

La propuesta fue revisada por el JNE y motivó la presentación del Proyecto de Ley 1313-2016/JNE, el 26 de abril del 2017, que regulaba en seis artículos las encuestas electorales (Titulo XII, artículos 344 a 349). El actual Anteproyecto de Ley (2020), mantiene el mismo número de dispositivos (artículos 345 al 350). Establece definiciones (artículo 345), contempla el Registro Electoral de Encuestadoras (artículo 346), precisa las obligaciones de los medios de comunicación (artículo 347), las limitaciones por razones temporales (artículo 348), la fiscalización a cargo del JNE (artículo 349), así como las infracciones y sanciones (artículo 350). Un cambio relevante es que la publicación de las encuestas puede efectuarse hasta 48 horas antes del día de las elecciones. En su Exposición de Motivos señala:

"Durante un proceso electoral, las encuestas y los sondeos de opinión toman importancia ya que tanto a las organizaciones políticas en contienda como a los medios de comunicación y a la opinión pública les interesa conocer las tendencias electorales.

Por un lado, están los instrumentos basados en técnicas especializadas con carácter científico, denominados encuestas; y por otro, los que carecen de este atributo, a los que se les denomina sondeos. El Proyecto del Código Electoral define las categorías de encuesta electoral y sondeo de opinión con ligeras modificaciones en relación a la norma reglamentaria vigente señalando que pueden existir otros mecanismos a través de los cuales se muestre la intención de voto, como por ejemplo los simulacros o las proyecciones."

57 Jurado Nacional De Elecciones. 2020. Anteproyecto de Ley de Código Electoral 2020.

Actualizado. Con Exposición de Motivos, Lima: JNE.

58 Exposición de Motivos del Proyecto N 590-2011-JNE. pp.251. 
El 23 de agosto del 2016, la Comisión de Constitución y Reglamento del Congreso -disuelto constitucionalmente por el entonces presidente Martín Vizcarra-, conformó el "Grupo de Trabajo de Estudio de la Reforma Electoral". Estuvo integrado por los entonces congresistas Patricia Donayre (Coordinadora), Gilbert Violeta y Marisol Espinoza. Posteriormente, se incorporaron Rosa María Bartra, Zacarías Lapa, Yonhy Lescano y Javier Velásquez Quesquén.

Posteriormente, el 12 de mayo del 2017, la congresista Donayre, presentó al presidente de la Comisión de Constitución, Miguel Torres, el Informe Final aprobado por unanimidad que contenía una propuesta de "Ley Electoral", que contaba con XVI títulos, 423 artículos y 12 disposiciones transitorias y finales. El Título XIII estaba referido a las "Encuestas" y contaba con ocho artículos (artículos 404 a 411). Disponía que el JNE “regula la realización, publicación y difusión de encuestas electorales y sondeos sobre intención de voto en período electoral y no electoral, así como el procedimiento de sanción por vulneración de las normas de la materia" (artículo 404). La propuesta autorizaba al JNE a desarrollarlos a través de un Reglamento 59 .

La referida propuesta en lo relativo a las encuestas, se inspiró en el Proyecto de Ley 1313-2016/JNE. La única diferencia consistía en que se precisaban las infracciones y sanciones, las cuales en la propuesta del JNE serían establecidas por reglamento (artículo 349).

En la sesión del 16 de mayo de la Comisión de Constitución y Reglamento, la congresista Donayre sintetizó "los temas que han sido materia de un mayor debate" y propuso que se apruebe un "cronograma de 10 sesiones para el debate, por capítulos, del texto presentado". El congresista Lescano propuso que "la propuesta de ley electoral sea considerado como un predictamen". El Informe Final

59 En sus ocho artículos, disponía lo siguiente:

a) El JNE regula y administra el Registro Electoral de Encuestadoras (REE). Regula la realización, publicación y difusión de encuestas electorales y sondeos sobre intención de voto en periodo electoral y no electoral, así como el procedimiento sancionador (artículo 404).

b) Define el significado de "encuesta electoral" y "sondeo de opinión" precisando que los medios de comunicación y las encuestadoras al difundir estos últimos deberán indicar que "Los resultados de este sondeo son referenciales" (artículo 405).

c) El REE es de carácter público. La inscripción, tiene vigencia de tres años, y autoriza a las encuestadoras a difundir y publicar los resultados de las encuestas y sondeos. El JNE regula los requisitos de inscripción, renovación, cancelación y demás aspectos administrativos (artículo 406).

d) Los medios de comunicación deben publicar determinada información (nombre de la encuestadora, número de partida asignada por el JNE, tamaño de la muestra, etc.). Las encuestadoras deben enviar a los medios de comunicación dicha información (artículo 407).

e) La publicación o difusión de encuestas y sondeos en medios de comunicación puede realizarse hasta el viernes anterior al día de las elecciones (artículo 408).

f) El JNE cumplirá labores de fiscalización sobre las encuestas (artículo 409) y se precisan las infracciones y sanciones aplicables (artículo 410). Finalmente, se establece la publicidad de los informes y anexos remitidos por las encuestadoras, luego de un año de cerrado el proceso electoral (artículo 411). 
fue aprobado en dicha sesión. No se sometió a votación el cronograma propuesto, y se descartó su consideración como un predictamen. Según el presidente de la Comisión era "necesario evaluarlo, debido a que propone sesiones que van más allá de su periodo como presidente de la Comisión".

El 06 de junio, el presidente de la Comisión sustentó los alcances de un predictamen sobre determinados proyectos en materia electoral sin centrarse en el Informe del Grupo de Trabajo. En otra sesión, al dar respuesta sobre la metodología a seguir para abordar la reforma electoral, señaló que "se estaría votando por tema en dictámenes, considerando el informe del grupo de trabajo en cada uno de los extremos que se iría votando". Quedó claro que el debate del mencionado Informe no se efectuaría en forma integral sino en función de los temas que la Comisión de Constitución estime prioritarios. Así sucedió. No hubo voluntad política para aprobar una reforma electoral integral.

Una nueva conformación de la Comisión de Constitución y Reglamento del Congreso, presidida por Úrsula Letona, aprobó el 05 de setiembre del 2017 su Plan de Trabajo que incluía entre las "reformas pendientes a priorizar" a la reforma electoral. Ella se realizaría por etapas abordando primero las "reformas legislativas urgentes". El Plan no mencionaba a las encuestas electorales. A la fecha, la regulación legal sobre las encuestas no ha sido modificada y la propuesta de reforma integral en materia electoral tampoco ha prosperado.

Durante el gobierno del Presidente Martín Vizcarra se plantearon diversas propuestas de reforma política. El gobierno, a través de la Resolución Suprema 228-2018-PCM de 21 de diciembre de 2018, creó por un periodo de dos meses una Comisión de Alto Nivel, presidida por Fernando Tuesta Soldevilla. La Comisión elaboró diversos proyectos de reforma constitucional y legal. Uno de ellos era el "Proyecto de ley que modifica la Ley Orgánica de Elecciones para establecer facilidades para el sufragio de la población en condiciones especiales, precisar el principio de neutralidad y garantizar una mejor gestión del proceso electoral". La citada propuesta planteaba la modificación del artículo 191 de la Ley Orgánica de Elecciones, señalando que la difusión de encuestas "puede efectuarse hasta veinticuatro (24) horas antes del día de las elecciones". Según su Exposición de Motivos:

“(...) la prohibición de difundir encuestas electorales no solo es una medida que ha quedado obsoleta, dada la imposibilidad de controlar su participación en las redes sociales, sino que, además, dicha prohibición afecta a los ciudadanos de manera diferenciada en función de su acceso a internet, a su ámbito de residencia (rural o urbano) y a su clase social, generando desigualdades en el acceso a la información $(\ldots)$.

(...) ha contribuido a la difusión de información falsa, con el objetivo de orientar comportamientos electorales (...)"60

60 Comisión de alto nivel para la reforma política. 2019. Hacia la democracia del Bicentenario. Lima: Konrad Adenauer Stiftung. pp. 346. 
La propuesta fue asumida por el Poder Ejecutivo y presentada el 10 de abril del 2019 al Congreso de la República como Proyecto de Ley 4193/2018-PE. Fue remitida a la Comisión de Constitución y Reglamento, sin que hasta el momento haya sido objeto de dictamen alguno.

Una reforma electoral en serio, que sistematice, modernice las diversas normas existentes, y corrija los problemas detectados resulta indispensable. Las Misiones de Observación Electoral de la OEA, desde el 2014 hasta la fecha, han señalado que “en Perú no existe un cuerpo normativo sistematizado e integral para la regulación electoral. Las reglas que rigen los procesos se encuentran dispersas en distintas leyes y reglamentos, lo cual dificulta su conocimiento por parte de quienes participan en la contienda". Por ello, la Comisión de Observación de la OEA, en su Informe Preliminar MOE-OEA, luego de realizarse la segunda vuelta electoral el 2021, ha recomendado "Unificar las normas vigentes en materia electoral en un cuerpo normativo, a través de la aprobación de un Código Electoral" 61. Lamentablemente, hasta el momento ello no ha sucedido.

\section{ii. Razones y temas clave para una regulación}

Al momento de discutir una posible regulación sobre las encuestas electorales pueden plantearse dos alternativas. Por un lado, privilegiar la autorregulación y, por otro, proponer una regulación que puede ir de un extremo reglamentarista a uno que solo contemple los temas clave dejando espacio a una reglamentación a cargo del JNE, sujeta a los lineamientos previstos por la ley. Una regulación básica existe en nuestro país desde 1984 (Ley 23903, publicada el 25 de agosto), es decir, hace aproximadamente 37 años.

Al margen del tema legal, existen aspectos éticos a considerar por los propios actores, especialmente, los medios de comunicación. Y es que, como lo señaló la Corte Constitucional de Colombia: "La difusión de las encuestas de opinión exige siempre un alto grado de responsabilidad social por parte de los medios de comunicación; de ahí que toda manipulación de la información sea un atentado directo contra la ética periodística y, jurídicamente, contra el derecho a la información imparcial y veraz que tienen los asociados" 62 . Los respectivos códigos de ética deberían abordar tales aspectos.

Una regulación de las encuestas electorales se justifica en la medida que pretenda garantizar los siguientes objetivos:

a) El acceso a la información a la ciudadanía y a las agrupaciones políticas en particular, sobre las tendencias electorales, así como fomentar la trasparencia y publicidad. Las personas "deben estar en condiciones de saber cómo se ha

61 Extraído de https://www.oas.org/documents/spa/press/Informe-Preliminar-Segunda-VueltaPeru-2021.pdf. Consulta realizada el día 19 de julio de 2021. Misión De Observación Electoral OEA

62 Sentencia C-488/1993, de 28 de octubre de 1993 
llegado a determinados resultados, qué se ha preguntado y cómo se ha respondido"63.

b) La posibilidad que las personas puedan adoptar una decisión informada al momento de tomar una decisión electoral, y que los medios de comunicación puedan contribuir a la formación de una opinión pública libre.

c) La objetividad de la información evitando la difusión de información inexacta, falsa o manipulada sobre las tendencias electorales.

d) El ejercicio de la libertad de empresa de las compañías o instituciones encuestadoras para cumplir libremente con sus actividades en el marco de una economía social de mercado.

e) Establecer mecanismos de fiscalización y sanción a cargo del JNE que respeten principios básicos $\mathrm{y}$, especialmente, el debido proceso que caracteriza a todo procedimiento administrativo sancionador.

Se trata de objetivos constitucionalmente legítimos que justifican la elaboración, procesamiento y difusión de las encuestas y sondeos de opinión y ratifican la relevancia "del papel que desempeñan las encuestas en los procesos electorales y (...) su regulación"64. En la actualidad, el impacto de las encuestas y sondeos adquiere mayor relevancia, debido a la facilidad de su divulgación a través de los diversos medios electrónicos.

Existen aspectos fundamentales que podrían ser considerados en una ley dejando que el JNE asuma su reglamentación. Por ejemplo, establecer algunas definiciones relevantes, precisar las funciones del JNE y del Registro Electoral de Encuestadoras, los derechos y deberes de las encuestadoras y de los medios de comunicación, la prohibición de publicar o divulgar los resultados de las encuestas antes del día de las elecciones, las infracciones y sanciones en caso de incumplimiento, las obligaciones de transparencia, entre otras. La ley debe ser el marco fundamental que una reglamentación no pueda superar. Ello con la finalidad de garantizar la seguridad jurídica y la predictibilidad. A nuestro juicio, una regulación básica sobre las encuestas electorales debería abordar los temas siguientes:

a) Precisar los alcances de las expresiones "encuestas electorales", "sondeos de opinión" y "simulacros de votación". Según la Exposición de Motivos del Proyecto de Ley 1313-2016/JNE presentado por el JNE, " pueden existir otros mecanismos a través de los cuales se muestre la intención de voto, como por ejemplo los simulacros".

b) Regular el Registro de Empresas Encuestadoras a cargo del JNE, que tiene carácter público, determinando sus funciones básicas.

c) Reconocer derechos a las empresas e instituciones encuestadoras registradas como tales. Entre ellos podemos mencionar: (i) ingresar a los locales de

63 VILLANUEVA, Ernesto. “Encuestas y Transparencia”. En Regulación de encuestas electorales en México, pp. 29.

64 DE LA PEÑA MENA, Ricardo. “El debate sobre las encuestas electorales en México en 2012”. En Revista Mexicana de Opinión Pública, Núm 20, enero-junio, 2016, pp.53. 
votación el día de las elecciones; (ii) circular libremente en los exteriores de los locales de votación, incluso luego del cierre de la votación; (iii) realizar entrevistas a los ciudadanos y ciudadanas; (iv) acceder a información pública de los organismos electorales; (v) las demás que establezca el reglamento. Las empresas e instituciones encuestadoras no cumplen el rol de un observador electoral y, por tanto, no se les aplica su estatuto normativo. Tienen funciones distintas. Por ello, sería importante reconocerle derechos y prerrogativas para el adecuado ejercicio de sus funciones, dado que su finalidad resulta constitucionalmente legítima pues contribuyen a la formación de una opinión pública informada.

d) Determinar las obligaciones y prohibiciones de las empresas e instituciones encuestadoras y medios de comunicación. Así, podemos mencionar: (i) no poder realizar "encuestas electorales" y "sondeos de opinión" sin estar previamente inscritas en el Registro de Empresas Encuestadoras; (ii) no divulgar "encuestas electorales" y "sondeos de opinión" que no cumplan con los requisitos objetivos previstos por la ley; (iii) prohibición de publicar los resultados de las "encuestas electorales" y "sondeos de opinión" el día de las elecciones y hasta la hora de cierre de la votación, (iv) remitir dentro de un plazo razonable de la publicación de la encuesta un informe a la Dirección Central de Gestión Institucional del JNE que respalde sus resultados.

e) Precisar los datos esenciales que deben ser publicados conjuntamente con la encuesta ("requisitos técnicos y de publicidad"65). La publicidad de la "ficha técnica" es muy relevante pero obviamente no "puede recoger todo, pues el espacio con que cuentan los medios de comunicación y la capacidad de captar la atención del público son, en su propia esencia, limitados". Estos requisitos son considerados como una "garantía de objetividad" 66 .

f) Detallar el contenido básico del Informe que deben remitir las encuestadoras al JNE luego de publicada una encuesta como respaldo de los resultados obtenidos. El Informe debería hacer referencia al cumplimiento de "las reglas o principios metodológicos básicos, universalmente aceptados, que deben seguir los organismos de sondeos a la hora de efectuar encuestas electorales objeto de publicación"67.

65 La Ley Orgánica 5/1985, de 19 de junio, Ley del Régimen Electoral General (España) precisa que: Artículo 69.- (...) 1. Los realizadores de todo sondeo o encuesta deben, bajo su responsabilidad, acompañarla de las siguientes especificaciones, que asimismo deben incluir toda publicación de las mismas:

a) Denominación y domicilio del organismo o entidad, pública o privada o de la persona física que haya realizado el sondeo, así como de la que haya encargado su realización.

b) Características técnicas del sondeo, que incluyan necesariamente los siguientes extremos: sistema de muestreo, tamaño de la muestra, margen de error de la misma, nivel de representatividad, procedimiento de selección de los encuestados y fecha de realización del trabajo de campo.

c) Texto íntegro de las cuestiones planteadas y número de personas que no han contestado a cada una de ellas.

66 SÁNCHEZ MUÑOZ, Oscar. La igualdad de oportunidades en las competiciones electorales. Madrid: Centro de Estudios Políticos y Constitucionales, 2007, pp.319.

67 GÁlVEZ MUÑOZ, Luis. “Organismos de sondeos, encuestas elecotales y Derecho”. En Revista Mexicana de Estudios Políticos, Núm 110, octubre-diciembre, 2000, pp.118. 
g) Determinación de los alcances del rol fiscalizador que corresponde al JNE, respecto a las empresas encuestadoras para que no restrinja o impida el normal ejercicio de las actividades de las empresas encuestadoras.

h) Regulación de las infracciones en que pueden incurrir las encuestadoras, los medios de comunicación y personas, respetando el principio de legalidad, estableciendo sanciones razonables y proporcionales, conforme a las pautas establecidas en el Texto Único Ordenando de la Ley del Procedimiento Administrativo General "que deben cumplir todas las entidades para poder ejercer la potestad sancionadora que se les confía"68. La sanción se impondrá a quien incumpla con la prohibición legal.

Estos podrían ser los temas básicos para una propuesta de regulación de las encuestas electorales, algunos de los cuales ya se encuentran previstos en el Reglamento vigente aprobado por el JNE. Es importante que se pueda debatir y aprobar el Código Electoral, que desde hace varios años permanece en la agenda pendiente.

\section{Reflexiones Finales}

Las encuestas electorales cumplen un rol informativo fundamental en una democracia moderna, pues permiten conocer la intención de voto de la ciudadanía en un momento determinado. Ante los riesgos de una posible manipulación y a fin de evitar un impacto negativo en la ciudadanía se han establecidos plazos para su divulgación, y obligaciones que deben cumplir las empresas e instituciones encuestadoras. Nos referimos a la inscripción en un registro oficial y la exigencia de fichas técnicas e informes. La transparencia sobre la manera como se obtienen resultados es fundamental para garantizar su objetividad. Por ello, nos parece razonable una opción reguladora y no una alternativa que solo promueva la autorregulación que identifica a los modelos anglosajones.

Las encuestas no brindan un pronóstico de los resultados electorales ni constituyen un oráculo de lo que sucederá el día de la elección. En países, como el nuestro, donde la ciudadanía decide su voto faltando pocos días para la elección o, a veces, el mismo día, es probable que los resultados obtenidos con anterioridad cambien en plazos muy breves.

En este contexto, es importante contar con una regulación razonable y proporcional que facilite la labor de las encuestadoras, contribuya a garantizar su objetividad y asegure una adecuada fiscalización. La existencia de un registro en manos del Jurado Nacional de Elecciones, la exigencia de fichas técnicas e informes apuntan a estos esfuerzos. Sin embargo, es preciso modificar el primer párrafo del artículo 191 de la Ley Orgánica de Elecciones que solo permite su difusión hasta el domingo anterior al día de las elecciones.

68 MORÓN URBINA, Juan Carlos. Comentarios a la Ley del Procedimiento Administrativo General. Lima: Gaceta Jurídica, 2015. 
Una medida prohibitiva de tal naturaleza cuyos antecedentes se remontan a 1984 no solo resulta inconstitucional por vulnerar los derechos a la libre expresión, información e igualdad, sino que carece de eficacia, resulta anticuada y favorece la difusión de noticias o encuestas falsas, pues los resultados de las encuestas se divulgan por internet o redes sociales. En definitiva, una alternativa razonable y proporcional sería permitir la divulgación de las encuestas hasta el día anterior a la fecha de la elección. Dicho tema debería evaluarse en el marco de una reforma electoral y política que sigue estando en la agenda pendiente del país. 